\title{
Analisis Pengaruh Orientasi Pasar terhadap Keunggulan Bersaing Melalui Kualitas Layanan Sebagai Variabel Intervening
}

\author{
Iqbal Arraniri \\ iqbal@uniku.ac.id \\ Program Studi Manajemen Fakultas Ekonomi Universitas Kuningan
}

\begin{abstract}
Abstrak
Komitmen Pemerintah terhadap sektor UMKM dengan mengeluarkan dari kebijakan relaksasi DNI (daftar Negatif Investasi) akan tetap menjadi kekhawatiran bagi para pelaku UMKM yang belum siap menghadapi disrupsi dalam persaingan bisnis yang semakin ketat. Hal ini diperkuat dengan pengaruh yang signifikan terhadap pertumbuhuan ekonomi mencapai 62 juta unit UMKM dengan serapan tenaga kerja sebesar 116 juta orang dan kontirbusi terhadap produk domestik bruto (PDB) mencapai 60\%. Kinerja bisnis yang tinggi memiliki peranan strategis jika dihadapkan dengan faktor eksternal yang lebih kuat pengaruhnya daripada faktor internal dalam menjaga keberlangsungan hidup UMKM, oleh kerena itu penerapan manajemen strategi sangat diperlukan bagi UMKM Kecamatan Kuningan Jawa Barat karena tidak semua memiliki daya tahan yang sama satu sama lainnya terhadap persaingan bisnis. Tujuan utama penelitian ini adalah menjelaskan kedudukan beberapa variable yang diteliti serta hubungan antara satu variabel dengan variabel lain untuk menekankan semakin pentingnya keunggulan bersaing dari UMKM. Dalam pandangan yang lebih luas, penelitian ini berfungsi sebagai sumber informasi yang akan mempromosikan UMKM menuju keunggulan bersaing. Akhirnya, penelitian ini akan memberikan beberapa kesimpulan yang tersedia dan rekomendasi konkrit.
\end{abstract}

Keyword; Orientasi Pasar; Kualitas Layanan; Keunggulan Bersaing

\begin{abstract}
The government's commitment to the MSME sector by removing from the DNI relaxation policy (Negative Investment list) will remain a concern for MSME players who are not ready to face disruption in increasingly fierce business competition. This is reinforced by a significant effect on economic growth reaching 62 million MSME units with a workforce absorption of 116 million people and a contribution to gross domestic product (GDP) reaching $60 \%$. High business performance has a strategic role when faced with external factors that are more influential than internal factors in maintaining the survival of MSMEs, therefore the implementation of strategic management is indispensable for MSMEs in Kuningan District, West Java because not all have the same endurance to one another. against business competition. The main objective of this research is to explain the position of some of the variables studied and the relationship between one variable and another to emphasize the increasing importance of the competitive advantage of MSMEs. In a broader view, this research serves as a source of information that will promote MSMEs towards competitive advantage. Finally, this study will provide some of the available conclusions and concrete recommendations.
\end{abstract}

Keyword: Market Orientation, Service Quality, Competitive Advantage 
Indonesian Journal Of Strategic Management

Vol 2, Issue 1, February 2019

DOI: https://doi.org/10.25134/ijsm.v2i1.1856

PENGANTAR

Beberapa negara yang terhimpun sebagai negara ASEAN telah memberikan perhatian penuh terhadap UMKM dengan membentuk kerja sama dalam memperkuat daya saing dan keberlangsungannya, yang dimulai sejak tahun 1985 kemudian diperkokoh dengan pembentukan ASEAN Strategic Actionn Plan for Small Medium Enterprises Development (SAP SMED 2012-2015) melalui Cetak Biru MEA 2015 yang dipertegas lagi melalui Cetak Biru MEA 2025 tentang peran UMKM sebagai tulang punggung perekonomian ASEAN, Menurut Ashariyadi Sesditjen Kerja sama ASEAN Kementerian Luar Negeri menyatakan sekitar 96 persen bentuk usaha di ASEAN adalah UMKM dengan kontribusi pada produk domestik bruto (PDB) sekitar 30\% $57 \%$, penyerapan tenaga kerja sekitar $50 \%$ - 95\%, dengan demikian sektor UMKM didorong untuk memiliki pola usaha yang kompetitif (ASHARIYADI, 2016). Menjadi pondasi perekonomian nasional jika didasarkan pada perhitungan BPS tahun 2015 yang mampu memberikan kontribusi PDB sebesar $61,41 \%$, dan tenaga kerja sebesar 96,71\% (Koperasi, Usaha, \& Menengah, 2017).

Seiring terjadinya penurunan PDB sebesar 1,41\% (Annisa Sulistyo Rini, 2018). Apakah kebijakan relaksasi DNI UMKM menjadi peluang atau ancaman tentunya akan tetap menjadi kekhawatiran bagi para pelaku bisnis yang memang belum siap bersaing pada era disrupsi, oleh karena itu sektor UMKM harus mampu menentukan
p-ISSN 2614-5391, e-ISSN 2614-2406

https://journal.uniku.ac.id/index.php/ijsm

keunggulan bersaing mengingat kemampuan bersaing yang dimiliki berbeda satu sama lainnya.

Persaingan merupakan salah satu faktor yang sering dikaji terkait faktor internal dan faktor eksternal yang mempengaruhi kinerja, sebagaimana faktor eksternal lebih kuat pengaruhnya terhadap keunggulan bersaing UMKM dari pada faktor internal (Osmani, 2015). Persaingan merupakan tantangan terbesar terutama persaingan bisnis yang berkaitan dengan para pesaing lokal dibandingkan pesaing asing (Africa, 2016). Saat ini kian bertambah jumlahnya dan terus mengembangkan produk atau jasa yang dihasilkan sebagai upaya mempertahankan keunggulan bersaing yang berpengaruh signifikan terhadap kinerja UMKM sehingga perlu lebih fokus dalam mengatur dan mengkaji faktor-faktor yang berkontribusi terhadap keunggulan bersaing agar dapat bertahan dalam persaingan (Sinaga \& Gallena, 2018).

Implikasi praktis bagi para pengelola UMKM dalam mengembangkan keunggulan bersaing dapat dilakukan melalui pengembangan orientasi pasar sebagai sumber daya dan kapabilitas yang potensial (Yuniari, Nyoman, Yasa, \& Giantari, 2018). Begitu juga orientasi pasar memiliki hubungan positif yang signifikan terhadap kualitas layanan sebagaimana penelitian yang dilakukan oleh Wanjiru (WANJIRU .H. KIMANI, 2016). Demikian halnya pertumbuhan dan keberlangsungan hidup UMKM tergantung kepada beberapa faktor 
Indonesian Journal Of Strategic Management

Vol 2, Issue 1, February 2019

DOI: https://doi.org/10.25134/ijsm.v2i1.1856
p-ISSN 2614-5391, e-ISSN 2614-2406

https://journal.uniku.ac.id/index.php/ijsm penting diantarnya kualitas layanan yang ditawarkan kepada konsumen sehingga dapat memenuhi harapannya, dan hal ini dapat membantu menarik konsumen baru dan mempertahankan konsumen lama demi mewujudkan keunggulan bersaing dan kinerja bisnis yang lebih baik karena kualitas layanan dapat mempengaruhi kepuasan konsumen (Culiberg, 2010). Jadi selama sektor UMKM dapat terus meningkatkan kualitas layanannya maka akan dapat meningkatkan keunggulan bersaing yang lebih baik dari pesaingnya.

Bagi UMKM yang telah menjadikan orientasi pasar tidak hanya fokus terhadap pemahaman karakter konsumen akan tetapi juga menjadikan sebagai budaya organisasi yang dapat menciptakan perilaku-perilaku untuk menciptakan superior value bagi pembeli dan superior performance bagi perusahaan maka akan memudahkan dalam menyusun strategi untuk mencapai keberhasilan yang berdasarkan pada kebutuhan dasar eksternal, keinginan dan permintaan pasar yang lebih baik dari pesaingnya, sehingga dapat dikatakan bahwa orientasi pasar dapat mempengaruhi keunggulan bersaing (Sulistyawati \& Semarang, n.d.). Fokus perhatian terhadap orientasi pasar dan keunggulan bersaing dapat menjadi karakteristik UMKM dalam mencapai keberlangsungan hidup usaha yang berkelanjutan sehingga tidak hanya cukup dengan memahami pasar akan tetapi perlu membangun komitmen pimpinan dan karyawannya untuk terus belajar lebih cepat dari pesaing sehingga menghasilkan kinerja yang unggul (Profile, 2018).

Para pelaku UMKM harus selalu tanggap mencermati berbagai permasalahan dalam persaingan yang semakin komprehensif mulai dari internal dan eksternal seperti teknologi, budaya organisasi, kompetensi karyawan, lingkungan persaingan, selera pelanggan yang dinamis, kebijakan pemerintah, dan disrupsi atau perubahan yang menuntut penguatan strategi bisnis tidak hanya dari offline menjadi online akan tetapi harus lebih sensitif dan beradaptasi dengan perubahan, dengan demikian harus mampu membangun keunggulan bersaing, sebagaimana dijelaskan oleh Day dan Wensley bahwa keunggulan bersaing memiliki dua pemahaman definisi yang berbeda tetapi saling berhubungan (Bersaing, Orientasi, \& Produk, 2018). Pemahaman pertama berpandangan pada basis sumber daya dan pemahanan kedua berpandangan pada kekuatan kompetitif. Jadi seiring ketatnya persaingan dan perubahan yang sangat dinamis menjadikan keunggulan bersaing menjadi hal yang mendesak dan penting bagi pelaku UMKM sehingga secara sadar selalu dekat dengan kebutuhan dan keinginan pasar.

Sektor UMKM dapat memiliki keunggulan bersaing berkelanjutan ketika mampu menerapkan strategi menciptakan nilai yang belum bisa dilakukan oleh pesaing dan keunggulan bersaing merupakan kemampuan organisasi melakukan aktivitas 
Indonesian Journal Of Strategic Management Vol 2, Issue 1, February 2019

DOI: https://doi.org/10.25134/ijsm.v2i1.1856

bisnisnya dengan cara yang berbeda berlandaskan pada strategi yang baik sebagaimana keunggulan bersaing dianggap sebagai tujuan strategi. Data dan informasi UMKM yang didapatkan dari Dinas KUKM Kabupaten Kuningan berdasarkan beberapa kecamatan yang ada pada tahun 2015- 2017 ditemukan bahwa Kecamatan Kuningan yang memiliki jumlah 54 UMKM (Lampiran 1) yang heterogen dan terbanyak dari kecamatan lainnya sehingga peluang terjadinya ancaman persaingan bisnis antar industri lebih ketat. Menjadi daya tarik bagi penulis untuk memulai penelitian dari Kecamatan Kuningan Jawa Barat melalui jenis penelitian eksplanatori yang bermaksud menjelaskan kedudukan beberapa variabel serta hubungan antara satu variabel dengan variabel lainnya.

\section{TINJAUAN LITERATUR}

\begin{tabular}{rrr}
\multicolumn{2}{c}{ Beberapa negara memiliki } \\
persepsi yang
\end{tabular} mendefinisikan UMKM secara teknis dinyatakan bahwa UMKM terbagi ke dalam tiga kriteria berdasarkan Komisi Eropa pada tahun 2001 (Kraja \& Osmani, 2013), yaitu:

\begin{tabular}{|l|l|l|l|}
\hline \multicolumn{1}{|c|}{ Kriteria } & Mikro & \multicolumn{1}{|c|}{ Kecil } & Menengah \\
\hline Maksimal Jumlah Karyawan & 9 & 49 & 249 \\
\hline Maksimal Perputaran Tahunan & n/a & 7 juta Euro & 40 juta Euro \\
\hline Maksimal Total Neraca Tahunan & n/a & 5 juta Euro & 27 juta Euro \\
\hline
\end{tabular}

Begitu juga mereka sepakat dengan pendapat Scot \& Bruce (1987) bahwa UMKM harus memiliki minimal tiga karakter:

1. Pengelolaan usaha dilakukan secara mandiri atau terpusat, dan
p-ISSN 2614-5391, e-ISSN 2614-2406

https://journal.uniku.ac.id/index.php/ijsm biasanya pemilik juga berfungsi sebagai manajer.

2. Kepemilikan modal oleh seorang atau sekelompok kecil.

3. Operasional usaha terfokus di wilayah lokal begitu juga pemilik dan pekerja biasanya dari daerah setempat. Undang-undang RI No. 20 tahun 2008 tentang usaha kecil mikro dan menengah mendefinisikannya dengan beberapa kriteria (Setio Sapto Nugroho, 2008), sebagai berikut:

1. Kriteria Usaha Mikro adalah sebagai berikut:

a. Memiliki kekayaan bersih paling banyak Rp50.000.000,00 (lima puluh juta rupiah) tidak termasuk tanah dan bangunan tempat usaha; atau

b. Memiliki hasil penjualan tahunan paling banyak Rp300.000.000,00 (tiga ratus juta rupiah)

2. Kriteria Usaha Kecil adalah sebagai berikut:

a. Memiliki kekayaan bersih lebih dari Rp50.000.000,00 (lima puluh juta rupiah) sampai dengan paling banyak Rp500.000.000,00 (lima ratus juta rupiah) tidak termasuk tanah dan bangunan tempat usaha; atau

b. Memiliki hasil penjualan tahunan lebih dari Rp300.000.000,00

(tiga ratus juta rupiah) sampai paling banyak Rp2.500.000.000,00 (dua milyar lima ratus juta rupiah).

3. Kriteria Usaha Menengah adalah sebagai berikut:

a. Memiliki kekayaan bersih lebih dari Rp500.000.000,00 (lima ratus juta rupiah) sampai dengan paling banyak 
Indonesian Journal Of Strategic Management

Vol 2, Issue 1, February 2019

DOI: https://doi.org/10.25134/ijsm.v2i1.1856
p-ISSN 2614-5391, e-ISSN 2614-2406

https://journal.uniku.ac.id/index.php/ijsm
Rp10.000.000.000,00 (sepuluh

milyar rupiah) tidak termasuk tanah dan bangunan tempat usaha; atau

b. Memiliki hasil penjualan tahunan lebih dari Rp2.500.000.000,00 (dua milyar lima ratus juta rupiah) sampai dengan paling banyak Rp50.000.000.000,00 (lima puluh milyar rupiah).

\section{ORIENTASI PASAR}

Berdasarakan literature menunjukkan bahwa tujuan utama suatu bisnis dalam orientasi pasar adalah profitabilitas, data lapangan menunjukkan bahwa laba dianggap sebagai komponen orientasi pasar dan profitabilitas dipandang sebagai konsekuensi dari orientasi pasar (Narver \& F., 1990). Konsep dasar orientasi pasar pada dasarnya terdiri dari dua perspektif: pertama, Perspektif perilaku atau proses dan kedua, budaya (Vázquez, Santos, \& Álvarez, 2001). Dari sudut pandang budaya, orientasi pasar dipahami sebagai budaya organisasi di Indonesia di mana pasar, pelanggan, dan pesaing merupakan poros utama dari modus operandi perusahaan. Dengan demikian, orientasi semacam itu menyiratkan adanya seperangkat nilai dan sikap bersama di seluruh organisasi. Dari perspektif perilaku atau operasi menyiratkan definisi konsep orientasi pasar yang menunjukkan tugas-tugas yang harus diselesaikan dalam organisasi untuk menempatkan budaya dalam praktik secara efektif.

\section{Definisi Orientasi Pasar}

Orientasi pasar dapat difahami dari dua perspekif: sebagai perilaku dan sebagai budaya. (Sukato, 2014). Dalam persaingan di pasar global orientasi pasar memiliki peranan penting bagi organisasi dan diperlukan tidak hanya dalam pemasaran akan tetapi juga diperlukan bagi manajemen, mendefinisikan orientasi pasar sebagai generasi organisasi intelijen pasar, menyebarluaskan dan menanggapi intelijen pasar lintas departemen dalam organisasi. Dengan istilah lain juga memahami orientasi pasar dari tiga aspek; generasi intelijen pasar, diseminasi dan responsive.

Generasi intelijen. Pengembangan kecerdasan pasar mengacu pada pengumpulan dan penilaian kebutuhan pelanggan saat ini dan di masa depan, ditambah dampak peraturan pemerintah, pesaing, teknologi, dan kekuatan lingkungan lainnya. Penyebaran intelijen. Intelijen pasar harus dikomunikasikan dan disebarluaskan ke seluruh organisasi baik dalam cara formal maupun informal. Perusahaan harus memiliki cara yang efektif untuk menyebarluaskan intelijen yang dihasilkan sehingga sangat penting bagi departemen yang berbeda untuk berkolaborasi dalam upaya penyebaran intelijen semacam itu. Ketanggapan.Komponen terakhir dari kerangka kerja yang menekankan respon dari perusahaan terhadap kecerdasan pasar yang dihasilkan dan disebarluaskan. Ketanggapan harus melibatkan pemilihan target pasar, merancang dan menyediakan produk dan layanan untuk kebutuhan pelanggan 
Indonesian Journal Of Strategic Management

Vol 2, Issue 1, February 2019

DOI: https://doi.org/10.25134/ijsm.v2i1.1856
p-ISSN 2614-5391, e-ISSN 2614-2406

https://journal.uniku.ac.id/index.php/ijsm saat ini

dan yang diharapkan, serta distribusi dan promosi produk.

Penciptaan intelijen pasar

mengacu pada pengumpulan informasi pasar yang mencakup seluruh organisasi yang berkaitan dengan kebutuhan pelanggan saat ini dan di masa mendatang, penyebaran informasi di seluruh departemen dan tanggapan organisasi yang luas terhadapnya (Njeru \& Kibera, 2014). Banyak pendapat lain juga menyebutkan bahwa orientasi pasar bukanlah suatu budaya akan tetapi satu set kegiatan dalam suatu organisasi (Maryam, Marzieh, \& Marzieh, 2014).

Orientasi pasar dapat didefinisian sebagai strategi kompetitif yang paling efisien menghasilkan jenis perilaku yang tepat untuk menciptakan nilai tambah bagi konsumen untuk menjamin hasil jangka panjang yang lebih baik bagi perusahaan, oleh karena itu orientasi pasar dapat difahami sebagai fokus perusahaan pada faktor internal dan eksternal yang didasarkan pada orientasi pelanggan, orientasi terhadap pesaing, dan koordinasi antarfungsional. Upaya menciptakan dan mempertahankan keunggulan bersaing perusaahaan dilakukan dengan menganalisis tindakan atas setiap kekuatan pasar dengan koordinasi yang tepat di antara fungsi-fungsinya. Dengan demikian orientasi pasar dikonseptualisasikan menjadi sembilan aspek (Maydeu- olivares \& Lado, n.d.):

1. Analisis pelanggan akhir;

2. Analisis pelanggan menengah (distributor)
3. Analisis pesaing;

4. Analisis lingkungan pasar;

5. Tindakan strategis pada pelanggan akhir;

6. Tindakan strategis pada pelanggan menengah (distributor);

7. Tindakan strategis pada pesaing;

8. Tindakan strategis di lingkungan pasar; dan

9. Koordinasi antar-fungsional Orientasi pasar dapat

didefinisikan sebagai suatu bentuk budaya organisasi di mana karyawan di seluruh organisasi berkomitmen untuk terus menciptakan nilai pelanggan superior, atau sebagai urutan kegiatan pemasaran yang mengarah pada kinerja yang lebih baik. Sebagian besar studi tentang orientasi pasar berkisar pada tiga komponen (Adrianus Philip Schalk, 2008).

\section{KUALITAS LAYANAN}

Kualitas layanan dapat menjadi instrumen untuk mengukur kinerja bisnis UMKM dan kepuasan konsumen jika dapat mengarahkan operasi bisnisnya sesuai dimensi ServQual atau kualitas layanan. Layanan adalah aktifitas yang ditawarkan dan tidak berwujud (tidak terlihat), tetapi terukur oleh satu pihak ke yang lain dengan imbalan uang untuk kepuasan. Namun, kualitas dalam penawaran yang memberikan kepuasan pelanggan. Ini mungkin telah mendorong banyak perusahaan untuk mengadopsi program manajemen mutu yang bertujuan untuk meningkatkan kualitas produk dan 
Indonesian Journal Of Strategic Management

Vol 2, Issue 1, February 2019

DOI: https://doi.org/10.25134/ijsm.v2i1.1856
p-ISSN 2614-5391, e-ISSN 2614-2406

https://journal.uniku.ac.id/index.php/ijsm proses pemasaran yang telah dibuktikan oleh Kotler, Armstrong, Saunders dan Wong, bahwa "kualitas memiliki dampak langsung pada kinerja produk, dan dengan demikian, pada kepuasan pelanggan" ("Servqual Model as Performance Evaluation Instrument for Small and Medium Sized Enterprises ( SME ): Evidence From Customers in Nigeria," 2016).

Kualitas layanan dapat mengukur seberapa baik tingkat layanan yang disampaikan sesuai dengan harapan pelanggan. Kualitas layanan yang memuaskan berarti sesuai dengan harapan pelanggan secara konsisten. Demikian Pendapat yang disepakati oleh para peneliti dan manajer perusahaan bahwa kualitas layanan melibatkan perbandingan harapan dengan kinerja (Parasuraman, Zeithaml, \& Berry, 2009).

Usaha Mikro Kecil Menengah, bagaimanapun, cenderung dianggap secara implisit dalam hubungan dengan pelanggan mereka dan karena itu masalah seputar layanan pelanggan dan kualitas layanan dalam konteks perusahaan kecil diabaikan. pentingnya meningkatkan kualitas layanan yang akan memandu perusahaan berkembang dalam mencapai sukses di pasar yang semakin kompetitif mutlak diperlukan. Menurut Zeithaml dikatakan bahwa sangat sulit untuk mendefinisikan dan mengukur kualitas layanan karena karakteristik uniknya seperti; intangibility, inseparability, perishability dan kurangnya kepemilikan. Adapun kerangka
SERVQUAL yang dikembangkan oleh Parasuraman et al. pada tahun 1988 menunjukkan bahwa kepuasan pelanggan didasarkan pada beberapa faktor daripada satu faktor. Lima dimensi yang diidentifikasi untuk mengukur kualitas layanan adalah bukti fisik, keandalan, daya tanggap, jaminan dan empati (Wijetunge, 2016a)

\section{KEUNGGULAN BERSAING}

Keunggulan bersaing adalah sejauh mana suatu organisasi mampu menciptakan posisi yang dapat dipertahankan atas kompetitornya, maksudnya kemampuan yang memungkinkan organisasi untuk membedakan dirinya dari pesaingnya. Literatur empiris telah cukup konsisten dalam mengidentifikasi harga / biaya, kualitas, pengiriman, dan fleksibilitas sebagai kemampuan bersaing yang penting. Selain itu, penelitian terbaru telah memasukkan persaingan berbasis waktu sebagai prioritas bersaing yang penting, dan mengidentifikasi waktu sebagai sumber keunggulan bersaing berikutnya. lima dimensi berikut: harga kompetitif, harga premium, kualitas nilai-ke-pelanggan, pengedaran yang dapat diandalkan, dan inovasi produksi. Adapun dimensi- dimensi yang digunakan untuk variabel keunggulan bersaing diadopsi dari Suhong Li, yang digunakan dalam penelitian ini adalah harga / biaya, kualitas, ketergantungan pengiriman, inovasi produk, dan waktu ke pasar (Li, Ragu-nathan, Ragu-nathan, \& Rao, 2006). 
Indonesian Journal Of Strategic Management

Vol 2, Issue 1, February 2019

DOI: https://doi.org/10.25134/ijsm.v2i1.1856
p-ISSN 2614-5391, e-ISSN 2614-2406

https://journal.uniku.ac.id/index.php/ijsm

\section{METODE, DATA DAN ANALISIS}

Penelitian ini menggunakan metode eksplanatory research untuk menjelaskan kedudukan-kedudukan beberapa variable yang diteliti serta hubungan antara satu variabel dengan variabel lain. Dalam penelitian ini akan dijelaskan mengenai Analisis Pengaruh Orientasi Pasar terhadap Keunggulan Bersaing UMKM dengan Keualitas Layanan sebagai Variabel Intervening.

Lokasi penelitian dipilih dengan dasar pertimbangan objek penelitian, tujuan yang hendak dicapai, kemudahan pengumpulan data, faktor efisiensi waktu dan biaya. Oleh karena itu penelitian akan dilakukan pada UMKM di Kecamatan Kuningan.

Penelitian ini menggunakan teknik sampling purposive yaitu teknik penentuan samel dengan pertimbangan tertentu. Dari teknik tersebut, diperoleh sampel sebanyak 54 orang pelaku atau juga pemilik UMKM di Kecamatan Kuningan. Populasi dalam penelitian adalah seluruh UMKM di Kabupaten Kuningan Jawa Barat. Cara pemilihan sampel (responden) yang digunakan dalam penelitian ini menggunakan teknik nonprobability sampling.

Pengukuran variabel-variabel dalam penelitian ini dilakukan dengan menggunakan pengukuran secara kuantitatif agar dapat mengadakan pembuktian empiris yang dapat dipercaya, sehingga dapat diukur pengaruh variabel yang satu terhadap yang lain, oleh karena itu pengukuran variabel memiliki fungsi yang penting dalam penelitian (Lela Nurlela Wati,
2018). Skala pengukuran variabel yang digunakan dalam penelitian ini adalah skala interval dengan menggunakan skala likert yang dapat menyatakan sikap, pendapat, dan persepsi seseorang atau kelompok, kategori, peringkat dan jarak construct yang diukur. Skala ini tidak hanya mengurutkan data dari tingkat yang paling tinggi ke tingkat yang terendah tetapi sebaliknya, juga memperhatikan jarak interval, atau dengan kata lain jarak interval adalah relatif sama.

Uji validitas digunakan untuk mengukur sah atau valid tidaknya suatu kuesioner. Alat pengukur atau instrumen apa pun dikatakan valid ketika mengukur apa yang diharapkan untuk diukur. (Pandey \& Meenu Mishra Pandey, 2015). Bilamana koofisien korelasi antara skor suatu indikator dengan skor total seluruh indikator sama atau lebih besar dari 0,3 ( $\mathrm{r} \geq 0,3)$, maka instrumen tersebut dianggap valid. Uji reliabilitas dalam penelitian ini menggunakan koefisien Alpha Cronbach (a). Apabila nilai $\alpha$ lebih besar dari 0,70 $(\alpha \geq 0,70)$ dapat ditafsirkan suatu hasil pengukuran realtif konsisten apabila pengukuran diulangi dua kali atau lebih dengan kata lain dapat diandalkan (Lela Nurlela Wati, 2018).

Analisis Path (Analisis Jalur) memiliki tujuan untuk menerangkan akibat langsung dan tidak langsung seperangkat variabel, sebagai variabel penyebab, atau bebas (eksogen), terhadap variabel lainya yang merupakan variabel akibat, atau terikat (endogen) (Muhidin \& Maman 
Indonesian Journal Of Strategic Management

Vol 2, Issue 1, February 2019

DOI: https://doi.org/10.25134/ijsm.v2i1.1856
p-ISSN 2614-5391, e-ISSN 2614-2406

https://journal.uniku.ac.id/index.php/ijsm
Abdurahman, 2017).

Analisis Inferensial adalah analisis data sampel yang dapat menjadi kesimpulan umum untuk sebuah populasi. Analisis Statistik inferensial membutuhkan asumsi- asumsi lain yang perlu dipenuhi mengikuti alat analisis yang digunakan. Metode analisis statistik yang digunakan dalam statistik inferensial adalah T-test, Anova, Analisis regresi, Analisis jalur, dan metode analisis lain tergantung tujuan penelitian. Dalam statistik inferensial harus ada pengujian hipotesis yang bertujuan untuk melihat apakah ukuran statistik yang digunakan dapat ditarik menjadi kesimpulan yang lebih luas dalam populasinya ("Pengertian STATISTIK DESKRIPTIF dan STATISTIK INFERENSIAL -

Globalstats Academic," n.d.).

\section{HASIL DAN DISKUSI}

Data terakhir diambil sejumlah 42 orang pelaku atau pemilik UMKM dari 54 sampel yang dijadikan responden di Kecamatan Kuningan karena sebagian sudah tidak beroperasi aktivitas bisnisnya berdasarkan data UMKM Kecamatan Kuningan pada tahun 2015 2017. Kabupaten Kuningan terletak pada titik koordinat $108^{\circ} 23-108^{\circ} 47$ Bujur Timur dan $6^{\circ} 47-7^{\circ} 12$ Lintang Selatan. Sedangkan ibu kotanya terletak pada titik koordinat $6^{\circ} 45-7^{\circ} 50$ Lintang Selatan dan $105^{\circ} 20-108^{\circ} 40$ Bujur Timur. Bagian timur wilayah kabupaten ini adalah dataran rendah, sedang di bagian barat berupa pegunungan, dengan puncaknya
Gunung Ceremai (3.076 m) di perbatasan dengan Kabupaten Majalengka. Gunung Ceremai adalah gunung tertinggi di Jawa Barat.

Dilihat dari posisi geografisnya terletak di bagian timur Jawa Barat berada pada lintasan jalan regional yang menghubungkan kota Cirebon dengan wilayah Priangan Timur dan sebagai jalan alternatif jalur tengah yang menghubungkan Bandung- Majalengka dengan Jawa Tengah. Secara administratif berbatasan dengan:

Sebelah Utara: Kabupaten Cirebon Sebelah Timur: Kabupate Brebes (Jawa Tengah) Sebelah Selatan : Kabupaten Ciamis dan Kabupaten Cilacap (Jawa Tengah) Sebelah Barat : Kabupaten Majalengka. ("Letak \& Keadaan Geografis Pemerintah Kabupaten Kuningan,” n.d.). Ekonomi dan Industri Kec. Kuningan:

\begin{tabular}{|l|l|l|}
\hline 1 & Bawang goreng & Cirendang \\
\hline 2 & Emping & $\begin{array}{l}\text { Karangtaw } \\
\text { an g }\end{array}$ \\
\hline 3 & $\begin{array}{l}\text { Kupat/Leupeut/Koec } \\
\text { a ng }\end{array}$ & Winduhaji \\
\hline 4 & Gemblong/Anyaman & Citangtu \\
\hline 5 & Opak Bakar & Cijoho \\
\hline 6 & $\begin{array}{l}\text { Jamur/Kerajina } \\
\text { n Perak }\end{array}$ & Ancaran \\
\hline 7 & Tahu & Kuningan \\
\hline 8 & $\begin{array}{l}\text { Minuman ringan } \\
\text { dari jahe/Makanan } \\
\text { olah Ubi }\end{array}$ & $\begin{array}{l}\text { Kedungaru } \\
\text { m }\end{array}$ \\
\hline 9 & Jeli & Ciporang \\
\hline 10 & Anyaman & Cibinuang \\
\hline
\end{tabular}

(Sumber: http//.kuningankab.go.id) 
Indonesian Journal Of Strategic Management

Vol 2, Issue 1, February 2019

DOI: https://doi.org/10.25134/ijsm.v2i1.1856

Pengujian Hipotesis Pertama

- Besarnya Pengaruh

Langsung Variabel X1terhadap variabelY $=\mathrm{x}=0,561 \times 0,561=0,3147$ $=(31,47 \%)$

- Besarnya Pengaruh Tidaklangsung Variabel X1terhadap variabel Y melalui variabel $\mathrm{X} 2$

$=\mathrm{x} \mathrm{x}=0,561 \times 0,776 \quad \mathrm{x}$

$0,116=0,0505=(5,05 \%)$

- Besarnya Pengaruh Total Variabel X1 terhadap Y

$=\left[\begin{array}{ll}\mathrm{x}\end{array}\right]+[\mathrm{x} x]=0,3147+0,0505=$ $0,3652=36,52 \%$

Dengan demikian pengaruh orientasi pasar (X1), terhadap keunggulan bersaing (Y), atau dapat diambil kesimpulan bahwa keunggulan bersaing ditentukan oleh orientasi pasar sebesar $36,52 \%$.

Pengujian Hipotesis Kedua

- Besarnya Pengaruh

Langsung Variabel X2terhadap variabelY

$=\mathrm{x}=0,116 \times 0,116=0,0134$

$=(01,34 \%)$

- Besarnya Pengaruh Tidaklangsung Variabel X2 terhadap variabel $\mathrm{Y}$ melaluivariabelX1 $=\mathrm{xx}=0,116 \mathrm{x} 0,776$ x $0,561=0,0505=(5,05 \%)$

- Besarnya Pengaruh Total Variabel $\mathrm{X} 2$ terhadap $\mathrm{Y}=\left[\begin{array}{ll}\mathrm{x} & ]\end{array}\right]+\left[\begin{array}{ll}\mathrm{x} & \mathrm{x}\end{array}\right]=$ $0,0134+0,0505=0,0639=6,39 \%$.

Dengan demikian terdapat pengaruh kualitas layanan (X2), terhadap keunggulan bersaing (Y), atau dapat diambil kesimpulan bahwa keunggulan bersaing ditentukan oleh kualitas layanan sebesar $6,39 \%$.
p-ISSN 2614-5391, e-ISSN 2614-2406

https://journal.uniku.ac.id/index.php/ijsm
Pengujian hipotesis ketiga

\begin{tabular}{|c|c|c|c|c|c|}
\hline \multicolumn{6}{|c|}{ ANONA: } \\
\hline Model & Sum of Squares & $\mathrm{df}$ & Mean Square & $F$ & Sig. \\
\hline Regression & 568,796 & 2 & 284,398 & 14,692 &, $000^{2}$ \\
\hline Residual & 754,961 & 39 & 19,358 & & \\
\hline Total & 1323,758 & 41 & & & \\
\hline
\end{tabular}

Kesimpulannya bahwa orientasi pasar dan kualitas layanan secara gabungan/simultan mempengaruhi keunggulan bersaing sebesar $43 \%$. Besarnya pengaruh lain diluar model regresi atau variabel residu tersebut dihitung dengan rumus : $1-0,43=$ 0,57 atau sebesar $57 \%$.

\begin{tabular}{|l|l|}
\hline \multicolumn{1}{|c|}{ Pengaruh variabel } & Persentase \\
\hline $\mathrm{X}_{1}$ terhadap Y & 36,52 \\
\hline $\mathrm{X}_{2}$ terhadap Y & 6,39 \\
\hline $\begin{array}{l}\mathrm{X}_{1}, \mathrm{X}_{2} \text { bersama-sama } \\
\text { terhadap Y }\end{array}$ & 43 \\
\hline Residu $\varepsilon$ terhadap Y & 57 \\
\hline
\end{tabular}

Sumber: hasil pengolahan data

\section{PEMBAHASAN}

Berdasarkan hasil review indikator yang sama menghasilkan nilai hubungan "sedang" untuk kualitas layanan dengan keunggulan bersaing sebesar 0,552, dan memiliki pengaruh positif tapi tidak signifikan untuk kualitas layanan terhadap keunggulan bersaing UMKM di Kecamatan Kuningan Jawa Barat, dan hal ini dimungkinkan karena mayoritas jenis UMKM di Kecamatan Kuningan bukan usaha jasa.Pengaruh variabel orientasi pasar dan kualitas layanan secara simultan terhadap keunggulan bersaing empiris terhadap UMKM kerajinan perak di Desa Celuk propinsi Bali, hipotesis penelitian mengenai pengaruh orientasi pasar 
Indonesian Journal Of Strategic Management

Vol 2, Issue 1, February 2019

DOI: https://doi.org/10.25134/ijsm.v2i1.1856
p-ISSN 2614-5391, e-ISSN 2614-2406

https://journal.uniku.ac.id/index.php/ijsm terhadap keunggulan bersaing memiliki pengaruh positif dan signifikan(Yuniari et al., 2018), diperkuat lagi oleh hasil kajian Sendhang yang manyatakan bahwa orientasi pasar berpengaruh positif terhadap keunggulan bersaing UKM bidang furniture di Kota Semarang (Sendhang Nurseto, 2014). Adapun penelitian ini dilakukan terhadap seluruh UMKM yang terdaftar di Dinas KUKM Kecamatan Kuningan mayoritas fokus produksi makanan dan minuman ringan dengan berbagai jenis produk yang satu sama lainnya berbeda, namun tetap menghasilkan hipotesis yang sama.

Berdasarkan hasil analisis terhadap seluruh sektor UMKM di Sri Langka ditemukan bahwa kualitas layanan yang ditawarkan oleh UMKM memiliki hubungan yang "kuat" dan signifikan terhadap keunggulan bersaing sebesar 0,785. Indikator penilaian kualitas layanan diadopsi dari model yang dkembangkan oleh Parasuraman dan disitasi oleh Barbara (Culiberg, 2010) juga disitasi oleh Wijetunge. Dengan menggunakan diperkuat dengan hasil penelitian yang menjelaskan bahwa orientasi pasar yang semakin baik dapat berpengaruh positif terhadap kualitas layanan sehingga berdampak terhadap kinerja perusahaan (Mempengaruhi, Layanan, Pribadiyanto, \& S, 2004). Hasil penelitian yang dilakukan oleh Akhmad Supriyanto et al. (Dan \& Perusahaan, 2017) menjelaskan tentang pengaruh positif orientasi pasar terhadap keunggulan bersaing UMKM. Penelitian dari Musnaini menjelaskan hubungan yang kuat untuk kualitas layanan dengan keunggulan bersaing dengan nilai koefisien determinasi sebesar 84,7\% (Ekonomi \& Jambi, 2011). Dengan demikian daimbil kesimmpulan bahwa orientasi pasar dan kualitas layanan dapat meningkatkan keunggulan bersaing UMKM di Kecamatan Kuningan.

\section{KESIMPULAN}

Untuk meningkatkan keunggulan bersaing UMKM sektor makanan \& minuman ringan maupun sektor kerajinan, dapat dilakukan dengan cara memfokuskan perhatian pada perbaikan dan peningkatan orientasi pasar sebagai budaya dan perilaku sehingga menjadi seperangkatnilai dan sikap bersama seluruh anggota perusahaan/UMKM, melalui variabel intervening meskipun tidak signifikan, kedudukan variabel orientasi pasar tetap berpengaruh positif dan signifikan terhadap keunggulan bersaing UMKM Kecamatan Kuningan sehingga tujuan strategi dapat tercapai.

\section{IMPLIKASI/BATASAN DAN SARAN}

Fokus perhatian strategi UMKM mestinya juga diarahkan pada peningkatan kualitas layanan sebagai upaya optimalisasi pengembangan lini produk di bidang jasa, sehingga perlu meningkatkan perbaikan beberapa indikator berikut: pelanggan tidak mengantri lama, karyawan memberitahu pelanggan waktu pelayanan, perusahaan selalu mempertimbangkan kebutuhan dan keinginan pelanggan, pengiriman produk ke pelanggan tepat waktu sesuai 
Indonesian Journal Of Strategic Management Vol 2, Issue 1, February 2019

DOI: https://doi.org/10.25134/ijsm.v2i1.1856

janji, pengiriman yang dapat diandalkan dari perusahaan, kreativitas produk yang dapat memenuhi kebutuhan pelanggan, menanggapi gagasan pelanggan terkait design-design produk, dan distribusi produk ke pasar yang cepat

\section{REFERENSI}

Adrianus Philip Schalk. (2008).Effectts off Markett Oriienttattiion on Busiiness Perfformance: Empiricall Evidence from Iceland. Marketing and International Business. Retrieved from www.vidskipti.hi.is

Africa, S. (2016). "Factors affecting the performance of small and medium enterprises in Factors affecting the performance of small and medium enterprises in KwaZulu-Natal, South Africa.https://doi.org/10.21511/ppm $.14(2-2) .2016 .03$

Annisa Sulistyo Rini. (2018). Jokowi

Pastikan UMKM Dicoret dari Relaksasi DNIe. Retrieved November 30, 2018, from http://finansial.bisnis.com/read/201 81128/9/864139/jokowi- pastikanumkm-dicoret-dari- relaksasi-dni

ASHARIYADI. (2016). Majalah Masyarakat ASEAN edisi 12. Mizana Khusnu Perdani, 4. https://doi.org/iSSn 2460-1683

Culiberg, B. (2010). identifying service quality dimensions as antecedents to
p-ISSN 2614-5391, e-ISSN 2614-2406

https://journal.uniku.ac.id/index.php/ijsm

customer satisfaction in retail banking, 12(3), 151-166.

Dan, B., \& Perusahaan, K. (2017). pengaruh orientasi pasar terhadap nilai inovasi, keunggulan, (September).https://doi.org/10.1886 0/ed.v2i1.3109

Ekonomi, F., \& Jambi, U. (2011). analisis kualitas layanan konsumen terhadap keunggulan bersaing jasa transportasi darat pada $\mathrm{pt}$. kereta api indonesia ( persero) kelas argo, (2), 1-8.

Koperasi, B., Usaha, D. A. N., \& Menengah, K. D. A. N. (2017). Arah kebijakan bidang koperasi dan usaha mikro, kecil dan menengah.

Kraja, Y., \& Osmani, E. (2013). competitive advantage and its impact in small and medium enterprises ( smes ) ( case of albania ), 9(16), 76-85.

Lela Nurlela Wati (2018). Metodologi Penelitian Terapan. (Momon, Ed.). Bandung: CV. Mujahid Press.

Maryam, S., Marzieh, T., \& Marzieh, G. (2014). Relationship among market orientation, service quality and organizational performance from perspective of Gonbad Kavoos Telecommunication firm employees, 5(3), 464-466.

Maydeu-olivares, A., \& Lado, N. (n.d.).Market orientation and 
Indonesian Journal Of Strategic Management Vol 2, Issue 1, February 2019

DOI: https://doi.org/10.25134/ijsm.v2i1.1856

business economic performance A mediated model. https://doi.org/10.1108/0956423 0310478837.

Mempengaruhi, Y., Layanan, K., Pribadiyanto, N., \& S, U. T. (2004). analisis faktor-faktor orientasi pasar relevansinya terhadap kinerja perusahaan, 1, 50-60.

Muhidin, S. A., \& Maman Abdurahman. (2017). analisis korelasi, regresi, dan jalur dalam penelitian (3rd ed.). Bandung: Cv. Pustaka Setia.

Narver, J. C., \& F., S. F. S. (1990). The Effect of a Market Orientation on Business Profitability. Journal of Marketing, 21.

Njeru, W. G., \& Kibera, P. F. N. (2014). the perceived effects of the three components of market orientation on, 10(25), 266-285

Osmani, E. (2015). Importance of external and internal environment in creation of competitive advantage to smes ( case of smes, in the northern region of, 11(13), 120-130.

Pengertian statistik deskriptif dan statistik inferensial -globalstats academic. (n.d.). profile, s. e. e. (2018). Orientasi pasar dan keunggulan bersaing (studi kasus penjualan komputer).
p-ISSN 2614-5391, e-ISSN 2614-2406

https://journal.uniku.ac.id/index.php/ijsm

Sendhang Nurseto. (2014). Pengaru

Orientasi Pasar Terhadap

Keunggulan Bersaing Melalui

Inovasi Pada Ukm Bidang Furniture

Di Kota Semarang. Jurnal Ilmu

Sosial,13(1).https://doi.org/https://d

oi.org/1 0.14710/jis.13.1.2014.17-

22

Servqual Model a Performance Evaluation Instrument for Small and Medium Sized Enterprises ( SME ): Evidence From Customers in Nigeia. (2016), 12(28), 520-540. https:// doi.org/10.19044/esj.2016.v12n28p 520

Setio Sapto Nugroho. (2008). UURI No20 tahun 2008 tentang usaha mikro, kecil dan menengah. Jakarta.

Sinaga, V. C., \& Gallena, J. T. (2018).The Influence of Competitive Advantage on Firm Performance of Small Medium Enterprises ( SMEs ), Lembang, Bandung, Indonesia : Case Study, 119(12), 15199-15220.

Sukato, N. (2014). The Implementation of Market Orientation and Innovation in SMEs, 4(5), 614-625. https://doi.org/10.6007/IJARBSS/ v4-i5/887

Sulistyawati, A. I., \& Semarang, U.(n.d.). model keunggulan bersaing pada umkm, (Senima 3), 351-359. 
Indonesian Journal Of Strategic Management Vol 2, Issue 1, February 2019

DOI: https://doi.org/10.25134/ijsm.v2i1.1856
p-ISSN 2614-5391, e-ISSN 2614-2406

https://journal.uniku.ac.id/index.php/ijsm

Vázquez, R., Santos, M. L., \& Álvarez, L. I. (2001). Market orientation, innovation and competitive strategies in industrial rms, 90, 69-90. https://doi.org/10.1080/096525 40010011493

Wanjiru .H. Kimani. (2016). Market Orientation And Business Perfomance In Kenyan Sme's.

Wijetunge, W. A. D. S. (2016a). Service Quality, Competitive Advantage and Business Performance in Service Providing SMEs in Sri Lanka, 6(7), 720-728.

Yuniari, W., Nyoman, N., Yasa, K., \& Giantari, I. G. A. K. (2018). The Role of Competitive Advantage In Mediating The Influence Of Market Orientation On Internationalization And Marketing Performance: A Study On Silver Craft Smes In Celuk Village, Bali Province, 6(10), 5571. 